\title{
Krasnoselskii-type algorithm for family of multi-valued strictly pseudo-contractive mappings
}

\author{
CE Chidume $^{1 *}$ and JN Ezeora ${ }^{1,2}$
}

"Correspondence:

cchidume@aust.edu.ng

'Mathematics Institute, African

University of Sciences and

Technology, Abuja, Nigeria

Full list of author information is

available at the end of the article

\begin{abstract}
A Krasnoselskii-type algorithm is constructed and the sequence of the algorithm is proved to be an approximate fixed point sequence for a common fixed point of a suitable finite family of multi-valued strictly pseudo-contractive mappings in a real Hilbert space. Under some mild additional compactness-type condition on the operators, the sequence is proved to converge strongly to a common fixed point of the family.
\end{abstract}

MSC: 47H04; 47H06; 47H15; 47H17; 47J25

Keywords: k-strictly pseudo-contractive mappings; multi-valued mappings; Hilbert spaces

\section{Introduction}

For several years, the study of fixed point theory for multi-valued nonlinear mappings has attracted, and continues to attract, the interest of several well known mathematicians (see, for example, Brouwer [1], Chang [2], Chidume et al. [3], Denavari and Frigon [4], Yingtaweesittikul [5], Kakutani [6], Nash [7, 8], Geanakoplos [9], Nadler [10], Downing and Kirk [11]).

Interest in such studies stems, perhaps, mainly from the usefulness of such fixed point theory in real-world applications, such as in Game Theory and Market Economy and in other areas of mathematics, such as in Non-Smooth Differential Equations (see e.g., [12]).

Game theory is perhaps the most successful area of application of fixed point theory for multi-valued mappings. However, it has been remarked that the applications of this theory to equilibrium problems in game theory are mostly static in the sense that while they enhance the understanding of conditions under which equilibrium may be achieved, they do not indicate how to construct a process starting from a non-equilibrium point that will converge to an equilibrium solution. Iterative methods for fixed points of multivalued mappings are designed to address this problem. For more details, one may consult [12-14].

Let $K$ be a nonempty subset of a normed space $E$. The set $K$ is called proximinal (see e.g., [15-17]) if for each $x \in E$, there exists $u \in K$ such that

$$
d(x, u)=\inf \{\|x-y\|: y \in K\}=d(x, K)
$$


where $d(x, y)=\|x-y\|$ for all $x, y \in E$. Every nonempty, closed and convex subset of a real Hilbert space is proximinal.

Let $C B(K)$ and $P(K)$ denote the families of nonempty, closed and bounded subsets, and of nonempty, proximinal and bounded subsets of $K$, respectively. The Hausdorff metric on $C B(K)$ is defined by

$$
D(A, B)=\max \left\{\sup _{a \in A} d(a, B), \sup _{b \in B} d(b, A)\right\} \quad \text { for all } A, B \in C B(K) .
$$

Let $T: D(T) \subseteq E \rightarrow C B(E)$ be a multi-valued mapping on $E$. A point $x \in D(T)$ is called a fixed point of $T$ if $x \in T x$. The fixed point set of $T$ is denoted by $F(T):=\{x \in D(T): x \in T x\}$.

A multi-valued mapping $T: D(T) \subseteq E \rightarrow C B(E)$ is called L-Lipschitzian if there exists $L>0$ such that

$$
D(T x, T y) \leq L\|x-y\| \quad \forall x, y \in D(T) .
$$

When $L \in(0,1)$ in (1.1), we say that $T$ is a contraction, and $T$ is called nonexpansive if $L=1$.

Several papers deal with the problem of approximating fixed points of multi-valued nonexpansive mappings (see, for example [15-20] and the references therein) and their generalizations (see e.g., [21, 22]).

Recently, Abbas et al. [18], introduced a one-step iterative process as follows, $x_{1} \in K$ :

$$
x_{n+1}=a_{n} x_{n}+b_{n} y_{n}+c_{n} z_{n}, \quad n \geq 1 .
$$

Using (1.2), Abbas et al. proved weak and strong convergence theorems for approximation of common fixed point of two multi-valued nonexpansive mappings in real Banach spaces. Very recently, Chidume et al. [12], introduced the class of multi-valued $k$-strictly pseudocontractive maps defined on a real Hilbert space $H$ as follows.

Definition 1.1 A multi-valued map $T: D(T) \subset H \rightarrow C B(H)$ is called $k$-strictly pseudocontractive if there exists $k \in(0,1)$ such that for all $x, y \in D(T)$,

$$
(D(T x, T y))^{2} \leq\|x-y\|^{2}+k\|x-y-(u-v)\|^{2} \quad \forall u \in T x, v \in T y .
$$

In the case that $T$ is single-valued, definition 1.1 reduces to the definition introduced and studied by Browder and Petryshn [23] as an important generalization of the class of nonexpansive mappings. Chidume et al. [12], proved strong convergence theorems for approximating fixed points of this class of mappings using a Krasnoselskii-type algorithm, [24] which is well known to be superior to the recursion formula of Mann [25] or Ishikawa [26].

In this paper, motivated by the results of Chidume et al. [12], Abbas et al. [18], Khastan [27], Eslamian [28], Shahzad and Zegeye [29] and Song and Wong [17], we introduce a new Krasnoselskii-type algorithm and prove strong convergence theorems for the sequence of the algorithm for approximating a common fixed point of a finite family of multi-valued strictly pseudo-contractive mappings in a real Hilbert space. Our results, under the setting of our theorems, generalize those of Abbas et al. [18] and Chidume et al. [12], which are 
themselves generalizations of many important results, from two multi-valued nonexpansive mappings, and a single multi-valued strictly pseudo-contractive mapping, respectively, to a finite family of multi-valued strictly pseudo-contractive mappings.

\section{Main result}

In the sequel, we shall need the following lemma whose proof can be found in Eslamian [28]. We reproduce the proof here for completeness.

Lemma 2.1 Let $H$ be a real Hilbert space. Let $\left\{x_{i}, i=1, \ldots, m\right\} \subset H$. For $\alpha_{i} \in(0,1), i=$ $1, \ldots, m$ such that $\sum_{i=1}^{m} \alpha_{i}=1$, the following identity holds:

$$
\left\|\sum_{i=1}^{m} \alpha_{i} x_{i}\right\|^{2}=\sum_{i=1}^{m} \alpha_{i}\left\|x_{i}\right\|^{2}-\sum_{i, j=1, i \neq j}^{m} \alpha_{i} \alpha_{j}\left\|x_{i}-x_{j}\right\|^{2} .
$$

Proof The proof is by induction. For $m=2,(2.1)$ reduces to the standard identity in Hilbert spaces. Assume that (2.1) is true for some $k \geq 2$, that is,

$$
\left\|\sum_{i=1}^{k} \alpha_{i} x_{i}\right\|^{2}=\sum_{i=1}^{k} \alpha_{i}\left\|x_{i}\right\|^{2}-\sum_{i, j=1, i \neq j}^{k} \alpha_{i} \alpha_{j}\left\|x_{i}-x_{j}\right\|^{2}
$$

Then

$$
\begin{aligned}
\left\|\sum_{i=1}^{k+1} \alpha_{i} x_{i}\right\|^{2}= & \alpha_{1}\left\|x_{1}\right\|^{2}+\left(1-\alpha_{1}\right)\left\|\sum_{i=2}^{k+1} \frac{\alpha_{i}}{\left(1-\alpha_{1}\right)} x_{i}\right\|^{2} \\
& -\alpha_{1}\left(1-\alpha_{1}\right)\left\|\sum_{i=2}^{k+1} \frac{\alpha_{i}}{\left(1-\alpha_{1}\right)}\left(x_{1}-x_{i}\right)\right\|^{2} \\
= & \alpha_{1}\left\|x_{1}\right\|^{2}+\left(1-\alpha_{1}\right)\left\|\sum_{i=1}^{k} \alpha_{i+1}^{\prime} x_{i+1}\right\|^{2} \\
& -\alpha_{1}\left(1-\alpha_{1}\right)\left\|\sum_{i=1}^{k} \alpha_{i+1}^{\prime}\left(x_{1}-x_{i+1}\right)\right\|^{2}, \quad \alpha_{i}^{\prime}:=\frac{\alpha_{i}}{\left(1-\alpha_{1}\right)} .
\end{aligned}
$$

Using (2.2) in (2.3), we obtain

$$
\begin{aligned}
\left\|\sum_{i=1}^{k+1} \alpha_{i} x_{i}\right\|^{2}= & \alpha_{1}\left\|x_{1}\right\|^{2}+\left(1-\alpha_{1}\right)\left[\sum_{i=1}^{k} \alpha_{i+1}^{\prime}\left\|x_{i+1}\right\|^{2}\right. \\
& \left.-\sum_{i, j=1, i \neq j}^{k} \alpha_{i+1}^{\prime} \alpha_{j+1}^{\prime}\left\|x_{i+1}-x_{j+1}\right\|^{2}\right] \\
& -\alpha_{1}\left(1-\alpha_{1}\right)\left[\sum_{i=1}^{k} \alpha_{i+1}^{\prime}\left\|\left(x_{1}-x_{i+1}\right)\right\|^{2}\right. \\
& \left.-\sum_{i, j=1, i \neq j}^{k} \alpha_{i+1}^{\prime} \alpha_{j+1}^{\prime}\left\|x_{i+1}-x_{j+1}\right\|^{2}\right]
\end{aligned}
$$




$$
\begin{aligned}
= & \sum_{i=1}^{k+1} \alpha_{i}\left\|x_{i}\right\|^{2}-\sum_{i=2}^{k+1} \alpha_{1} \alpha_{i}\left\|\left(x_{1}-x_{i}\right)\right\|^{2} \\
& -\sum_{i, j=2, i \neq j}^{k+1} \alpha_{i} \alpha_{j}\left\|x_{i}-x_{j}\right\|^{2} \\
= & \sum_{i=1}^{k+1} \alpha_{i}\left\|x_{i}\right\|^{2}-\sum_{i, j=1, i \neq j}^{k+1} \alpha_{i} \alpha_{j}\left\|x_{i}-x_{j}\right\|^{2} .
\end{aligned}
$$

Therefore, by induction, we find that (2.1) is true. This completes the proof.

We now prove the following theorem.

Theorem 2.2 Let $K$ be a nonempty, closed and convex subset of a real Hilbert space $H$ and $T_{i}: K \rightarrow C B(K)$ be a finite family of multi-valued $k_{i}$-strictly pseudo-contractive mappings, $k_{i} \in(0,1), i=1, \ldots, m$ such that $\bigcap_{i=1}^{m} F\left(T_{i}\right) \neq \emptyset$. Assume that for $p \in \bigcap_{i=1}^{m} F\left(T_{i}\right), T_{i} p=\{p\}$. Let $\left\{x_{n}\right\}$ be a sequence defined by $x_{0} \in K$,

$$
x_{n+1}=\lambda_{0} x_{n}+\lambda_{1} y_{n}^{1}+\lambda_{2} y_{n}^{2}+\cdots+\lambda_{m} y_{n}^{m},
$$

where $y_{n}^{i} \in T_{i} x_{n}, n \geq 1$ and $\lambda_{i} \in(k, 1), i=0,1, \ldots, m$, such that $\sum_{i=0}^{m} \lambda_{i}=1$ and $k:=$ $\max \left\{k_{i}, i=1, \ldots, m\right\}$. Then $\lim _{n \rightarrow \infty} d\left(x_{n}, T_{i} x_{n}\right)=0 \forall i=0, \ldots, m$.

Proof Let $p \in \bigcap_{i=1}^{m} F\left(T_{i}\right)$. Then

$$
\left\|x_{n+1}-p\right\|^{2}=\left\|\lambda_{0}\left(x_{n}-p\right)+\sum_{i=1}^{m} \lambda_{i}\left(y_{n}^{i}-p\right)\right\|^{2}:=\left\|\sum_{i=0}^{m} \lambda_{i} z_{i}\right\|^{2},
$$

where $z_{0}=\left(x_{n}-p\right), z_{i}=\left(y_{n}^{i}-p\right), i=1, \ldots, m$, and $\sum_{i=1}^{m} \lambda_{i} z_{i}=\sum_{i=1}^{m} \lambda_{i}\left(y_{n}^{i}-p\right)$.

Using Lemma 2.3 of [12] and the identity (2.1), we obtain the following estimates:

$$
\begin{aligned}
\left\|x_{n+1}-p\right\|^{2}= & \lambda_{0}\left\|x_{n}-p\right\|^{2}+\sum_{i=1}^{m} \lambda_{i}\left\|y_{n}^{i}-p\right\|^{2} \\
& -\sum_{i=1}^{m} \lambda_{i} \lambda_{0}\left\|x_{n}-y_{n}^{i}\right\|^{2}-\sum_{i, j=1, i \neq j}^{m} \lambda_{i} \lambda_{j}\left\|y_{n}^{i}-y_{n}^{j}\right\|^{2} \\
\leq & \lambda_{0}\left\|x_{n}-p\right\|^{2}+\sum_{i=1}^{m} \lambda_{i}\left\|y_{n}^{i}-p\right\|^{2}-\sum_{i=1}^{m} \lambda_{i} \lambda_{0}\left\|x_{n}-y_{n}^{i}\right\|^{2} \\
\leq & \lambda_{0}\left\|x_{n}-p\right\|^{2}+\sum_{i=1}^{m} \lambda_{i}\left(D\left(T_{i} x_{n}, T_{i} p\right)\right)^{2}-\sum_{i=1}^{m} \lambda_{i} \lambda_{0}\left\|x_{n}-y_{n}^{i}\right\|^{2} \\
= & \left\|x_{n}-p\right\|^{2}-\sum_{i=1}^{m} \lambda_{i}\left(\lambda_{0}-k\right)\left\|x_{n}-y_{n}^{i}\right\|^{2} .
\end{aligned}
$$

Thus, since $\lambda_{i} \in(k, 1)$, we obtain

$$
\sum_{i=1}^{m}\left\|x_{n}-y_{n}^{i}\right\|^{2} \leq \frac{1}{\left(\lambda_{0}-k\right) k}\left(\left\|x_{n}-p\right\|^{2}-\left\|x_{n+1}-p\right\|^{2}\right) \quad \forall n \geq 1 .
$$


This implies that, for each $i=1,2, \ldots, m, \sum_{n=1}^{\infty}\left\|x_{n}-y_{n}^{i}\right\|^{2}<\infty$. Hence, $\lim _{n \rightarrow \infty}\left\|x_{n}-y_{n}^{i}\right\|=$ 0 , for each $i=1, \ldots, m$. Since $y_{n}^{i} \in T_{i} x_{n}, i=1, \ldots, m$, we have $0 \leq d\left(x_{n}, T_{i} x_{n}\right) \leq\left\|x_{n}-y_{n}^{i}\right\|$ and so

$$
\lim _{n \rightarrow \infty} d\left(x_{n}, T_{i} x_{n}\right)=0 .
$$

This completes the proof.

Definition 2.3 A mapping $T: K \rightarrow C B(K)$ is called hemicompact if, for any sequence $\left\{x_{n}\right\}$ in $K$ such that $d\left(x_{n}, T x_{n}\right) \rightarrow 0$ as $n \rightarrow \infty$, there exists a subsequence $\left\{x_{n_{k}}\right\}$ of $\left\{x_{n}\right\}$ such that $x_{n_{k}} \rightarrow p \in K$. We note that if $K$ is compact, then every multi-valued mapping $T: K \rightarrow C B(K)$ is hemicompact.

Theorem 2.4 Let $K$ be a nonempty, closed and convex subset of a real Hilbert space $H$ and $T_{i}: K \rightarrow C B(K)$ be a finite family of multi-valued $k_{i}$-strictly pseudo-contractive mappings, $k_{i} \in(0,1), i=1, \ldots, m$ such that $\bigcap_{i=1}^{m} F\left(T_{i}\right) \neq \emptyset$. Assume that for $p \in \bigcap_{i=1}^{m} F\left(T_{i}\right), T_{i} p=\{p\}$ and $T_{i}, i=1, \ldots, m$ is hemicompact and continuous. Let $\left\{x_{n}\right\}$ be a sequence defined by $x_{0} \in K$,

$$
x_{n+1}=\lambda_{0} x_{n}+\lambda_{1} y_{n}^{1}+\lambda_{2} y_{n}^{2}+\cdots+\lambda_{m} y_{n}^{m},
$$

where $y_{n}^{i} \in T_{i} x_{n}, n \geq 1$ and $\lambda_{i} \in(k, 1), i=0,1, \ldots, m$ such that $\sum_{0=1}^{m} \lambda_{i}=1$ with $k:=$ $\max \left\{k_{i}, i=1, \ldots, m\right\}$. Then the sequence $\left\{x_{n}\right\}$ converges strongly to an element of $\bigcap_{i=1}^{m} F\left(T_{i}\right)$.

Proof From Theorem 2.2, we have $\lim _{n \rightarrow \infty} d\left(x_{n}, T_{i} x_{n}\right)=0, i=1, \ldots, m$. Since $T_{i}, i=$ $1, \ldots, m$, is hemicompact, there exists a subsequence $\left\{x_{n_{k}}\right\}$ of $\left\{x_{n}\right\}$ such that $x_{n_{k}} \rightarrow q$ as $k \rightarrow \infty$ for some $q \in K$. Moreover, by continuity of $T_{i}, i=1, \ldots, m$, we also have $d\left(x_{n_{k}}, T_{i} x_{n_{k}}\right) \rightarrow d\left(q, T_{i} q\right), i=1, \ldots, m$ as $k \rightarrow \infty$. Therefore, $d\left(q, T_{i} q\right)=0, i=1, \ldots, m$ and so $q \in F\left(T_{i}\right)$. Setting $p=q$ in the proof of Theorem 2.2, it follows from inequality (2.6) that $\lim _{n \rightarrow \infty}\left\|x_{n}-q\right\|$ exists. So, $\left\{x_{n}\right\}$ converges strongly to $q \in \bigcap_{i=1}^{m} F\left(T_{i}\right)$. This completes the proof.

The following is an immediate corollary of Theorem 2.4. The proof basically follows as the proof of its analog for single multi-valued strictly pseudo-contractive map in Chidume et al. [12]. The proof is therefore omitted.

Corollary 2.5 Let $K$ be a nonempty, compact and convex subset of a real Hilbert space $H$ and $T_{i}: K \rightarrow C B(K)$ be a finite family of multi-valued $k_{i}$-strictly pseudo-contractive mappings, $k_{i} \in(0,1), i=1, \ldots$, m such that $\bigcap_{i=1}^{m} F\left(T_{i}\right) \neq \emptyset$. Assume that for $p \in \bigcap_{i=1}^{m} F\left(T_{i}\right)$, $T_{i} p=\{p\}$ and $T_{i}, i=1, \ldots, m$ is continuous. Let $\left\{x_{n}\right\}$ be a sequence defined by $x_{0} \in K$,

$$
x_{n+1}=\lambda_{0} x_{n}+\lambda_{1} y_{n}^{1}+\lambda_{2} y_{n}^{2}+\cdots+\lambda_{m} y_{n}^{m},
$$

where $y_{n}^{i} \in T_{i} x_{n}, n \geq 1$ and $\lambda_{i} \in(k, 1), i=0,1, \ldots, m$ such that $\sum_{0=1}^{m} \lambda_{i}=1$ with $k:=$ $\max \left\{k_{i}, i=1, \ldots, m\right\}$. Then the sequence $\left\{x_{n}\right\}$ converges strongly to an element of $\bigcap_{i=1}^{m} F\left(T_{i}\right)$. 
Remark 2.6 In Theorem 2.4, the continuity assumption on $T_{i}, i=1, \ldots, m$ can be dispensed with if we assume that for every $x \in K, T_{i} x, i=1, \ldots, m$ is proximinal and weakly closed.

Remark 2.7 If we set $i=1$ in all the results obtained in this paper, we recover the results of Chidume et al. [12].

Remark 2.8 The recursion formulas studied in this paper are of the Krasnoselkii type (see e.g. [24]) which is well known to be superior to the recursion formula of either the Mann algorithm or the so-called Ishikawa-type algorithm.

Remark 2.9 Our theorems and corollary improve the results of Chidume et al. [12] from single multi-valued strictly pseudo-contractive mapping to finite family of multi-valued strictly pseudo-contractive mappings. Furthermore, under the setting of Hilbert space, our theorems and corollary improve the convergence theorems for multi-valued nonexpansive mappings to the more general class of multi-valued strictly pseudo-contractive mappings studied in Sastry and Babu [15], Panyanak [16], Song and Wang [17], Shahzad and Zegeye [29] and Abbas et al. [18]. Also, in all our algorithms, $y_{n} \in T x_{n}$ is arbitrary and is not required to satisfy the very restrictive condition, ' $y_{n} \in T\left(x_{n}\right)$ such that $\left\|y_{n}-x^{*}\right\|=d\left(x^{*}, T x_{n}\right)$ ' imposed in [15-18, 20, 29].

For examples of multi-valued maps such that, for each $x \in K$, the set $T x$ is proximinal and weakly closed, the reader may consult Chidume et al. [12].

\section{Competing interests}

The authors declare that they have no competing interests.

Authors' contributions

All authors contributed equally to the writing of this paper. All authors read and approved the final manuscript.

\section{Author details}

${ }^{1}$ Mathematics Institute, African University of Sciences and Technology, Abuja, Nigeria. ${ }^{2}$ Department of Ind. Mathematics and Statistics, Ebonyi State University, Abakaliki, Nigeria.

Received: 24 November 2013 Accepted: 31 March 2014 Published: 07 May 2014

\section{References}

1. Brouwer, LEJ: Über Abbildung von Mannigfaltigkeiten. Math. Ann. 71(4), 598 (1912)

2. Chang, KC, et al:: Convergence theorems for some multi-valued generalized nonexpansive mappings. Fixed Point Theory Appl. 2014, 33 (2014)

3. Chidume, CE, et al.: Krasnoselskii-type algorithm for fixed points of multivalued strictly pseudo-contractive mappings. Fixed Point Theory Appl. 2013, 58 (2013)

4. Denavari, T, Frigon, M: Fixed point results for multivalued contractions on a metric space with a graph. J. Math. Anal. Appl. 405, 507-517 (2013)

5. Yingtaweesittikul, H: Suzuki type fixed point theorems for generalized multi-valued mappings in $b$-metric spaces. Fixed Point Theory Appl. 2013, 215 (2013)

6. Kakutani, S: A generalization of Brouwer's fixed point theorem. Duke Math. J. 8(3), 457-459 (1941)

7. Nash, JF: Non-cooperative games. Ann. Math. (2) 54, 286-295 (1951)

8. Nash, JF: Equilibrium points in $n$-person games. Proc. Natl. Acad. Sci. USA 36(1), $48-49$ (1950)

9. Geanakoplos, J: Nash and Walras equilibrium via Brouwer. Econ. Theory 21, 585-603 (2003)

10. Nadler, SB Jr: Multivalued contraction mappings. Pac. J. Math. 30, 475-488 (1969)

11. Downing, D, Kirk, WA: Fixed point theorems for set-valued mappings in metric and Banach spaces. Math. Jpn. 22(1), 99-112 (1977)

12. Chidume, CE, Chidume, CO, Djitte, N, Minjibir, MS: Convergence theorems for fixed points of multivalued strictly pseudo-contractive mappings in Hilbert spaces. Abstr. Appl. Anal. 2013, Article ID 629468 (2013)

13. Chang, KC: The obstacle problem and partial differential equations with discontinuous nonlinearities. Commun. Pure Appl. Math. 33, 117-146 (1980)

14. Erbe, $L$, Krawcewicz, W: Existence of solutions to boundary value problems for impulsive second order differential inclusions. Rocky Mt. J. Math. 22, 1-20 (1992) 
15. Babu, GVR, Sastry, KPR: Convergence of Ishikawa iterates for a multi-valued mapping with a fixed point. Czechoslov. Math. J. 55, 817-826 (2005)

16. Panyanak, B: Mann and Ishikawa iteration processes for multi-valued mappings in Banach spaces. Comput. Math. Appl. 54, 872-877 (2007)

17. Song, Y, Wang, H: Erratum to "Mann and Ishikawa iterative processes for multi-valued mappings in Banach spaces". Comput. Math. Appl. 54, 872-877 (2007)

18. Abbas, M, Khan, SH, Khan, AR, Agarwal, RP: Common fixed points of two multi-valued nonexpansive mappings by one-step iterative scheme. Appl. Math. Lett. 24, 97-102 (2011)

19. Yildirim, I, Khan, SH: Fixed points of multivalued nonexpansive mappings in Banach spaces. Fixed Point Theory Appl. 2012, 73 (2012). doi:10.1186/1687-1812-2012-73

20. Khan, SH, Yildirim, I, Rhoades, BE: A one-step iterative scheme for two multi-valued nonexpansive mappings in Banach spaces. Comput. Math. Appl. 61, 3172-3178 (2011)

21. Daffer, PZ, Kaneko, H: Fixed points of generalized contractive multi-valued mappings. J. Math. Anal. Appl. 192 655-666 (1995)

22. Garcia-Falset, J, Lorens-Fuster, E, Suzuki, T: Fixed point theory for a class of generalised nonexpansive mappings. J. Math. Anal. Appl. 375, 185-195 (2011)

23. Browder, FE, Petryshyn, WV: Construction of fixed points of nonlinear mappings in Hilbert spaces. J. Math. Anal. Appl. 20, 197-228 (1967)

24. Krasnosel'skiï, MA: Two observations about the method of successive approximations. Usp. Mat. Nauk 10, 123-127 (1955)

25. Mann, WR: Mean value methods in iterations. Proc. Am. Math. Soc. 4, 506-510 (1953)

26. Ishikawa, S: Fixed points by a new iteration method. Proc. Am. Math. Soc. 44, 147-150 (1974)

27. Khastan, $A$, et al:: Schauder fixed point theorem in semilinear spaces and its application to fractional differential equations with uncertainty. Fixed Point Theory Appl. 2014, 21 (2014)

28. Eslamian, M: Hybrid method for equilibrium problems and fixed point problems of finite families of nonexpansive semigroups. Rev. R. Acad. Cienc. Exactas Fís. Nat., Ser. A Mat. 107(2), 299-307 (2003)

29. Shahzad, N, Zegeye, H: On Mann and Ishikawa iteration schemes for multi-valued maps in Banach spaces. Nonlinear Anal. 71, 838-844 (2009)

10.1186/1687-1812-2014-111

Cite this article as: Chidume and Ezeora: Krasnoselskii-type algorithm for family of multi-valued strictly pseudo-contractive mappings. Fixed Point Theory and Applications 2014, 2014:111

\section{Submit your manuscript to a SpringerOpen ${ }^{\ominus}$ journal and benefit from:}

- Convenient online submission

- Rigorous peer review

Immediate publication on acceptance

- Open access: articles freely available online

- High visibility within the field

- Retaining the copyright to your article 